\title{
The influence of network characteristics and environmental conditions on voltage dip performance in MV networks
}

\author{
L. Tenti ${ }^{1}$, R. Chiumeo ${ }^{1}$, C. Gandolfi ${ }^{1}$ and L. Garbero ${ }^{1}$ \\ ${ }^{1}$ RSE S.p.A. Ricerca sul Sistema Energetico \\ Via Rubattino 54, 20134 Milano (Italy) \\ Phone/Fax number:+0039 02 3992.5126, e-mail: liliana.tenti@ rse-web.it, riccardo.chiumeo@ rse-web.it, \\ chiara.gandolfi@rse-web.it, luciano.garbero@ rse-web.it
}

\begin{abstract}
The paper is focused on the possible influence that some network characteristics (i.e. network configuration, type of neutral operation, geographical area, lines and cable length...) and environmental phenomena (lighting) may have on voltage dip performance in Medium Voltage (MV) networks. The investigation has been performed by applying both correlation techniques and Multiple Linear Regression analysis (MLR) on the voltage dips collected along several years of monitoring by the Italian MV network monitoring system QuEEN. As to the network characteristics and environmental factors used in the performed analysis they are referred to the data supplied in the past for the monitoring system and to the lighting data provided by the Italian lightning location system $\operatorname{SIRF}^{1}$. The percentage contribution of each network and environmental factor to the voltage dips statistic, irrespective of the other parameters, have been evaluated by multiple linear regression methods. The results of these analysis confirm that the overhead line length has got a significant influence on the phenomena while cable lines length has, as expected, only a negligible effect. The influence of lightning seems to be not so critical as expected and this happen also with the neutral type of operation while voltage dips performances depend, in a non-negligible way, on the belonging to a geographical area.
\end{abstract}

\section{Key words}

Voltage dip indices, multiple regression analysis, correlation, network characteristics, environmental factors, lightning.

\section{Introduction}

The influence of the principal network parameters and of the lightning density on voltage dips statistics has been investigated since the beginning of the monitoring campaign of the Italian MV distribution network in order to get a better knowledge of the possible causes of this voltage disturbance. Referring in particular to the voltage dips data collected in 2006 during the spring-summer period, at that time it was possible to assess a good correlation (correlation index $=0,93$ ) between the average

\footnotetext{
1 The SIRF system (Sistema Italiano di Rilevamento Fulmini ) is operate by CESI S.p.A.
}

number of voltage dips per week and the averaged stroke density in Italy as monitored by the Italian lightning location system SIRF [1]. Besides the seasonal limitations the analysis at that time were referred only to the voltage dip statistic collected by a limited number of MV bus-bars of HV/MV substations, all characterized by compensated neutral operation. More detailed analysis were performed on voltage dip statistics collected during the two-years period $2006 \div 2007$ by applying multiple linear regression analysis (MLR) in order to evaluate the influence of the different network and environmental parameters on the number of voltage dips in an independent way [2], [3]. In fact the add value of MLR is that it can be used to investigate the influence of each single network characteristic on the number of voltage dips, independently from all the other parameters, a result which cannot be reached by analysing voltage dip performance by simple MV networks aggregations, a sort of analysis which is however always feasible in the QuEEN system.

The first regression models implemented considered, as the main environmental factor to take into account, the averaged stroke density to soil per week associated to each Italian "Provincia" or district where a power quality monitoring unit had been installed. According to those models the aerial line length appeared to be able to take properly into account both lightning and the other faults producers factors (occasional contacts with external objects, components' defects, insulators' pollution). In this frame the main object of this work has been that of confirming the validity of the results of the previous analysis having now at disposal a more local measure of the average stroke density to soil in comparison with the provincial ones and dealing with voltage dips data collected over a tree-years monitoring period (2009 $\div$ 2011) at $400 \mathrm{HV} / \mathrm{MV}$ primary substations. More in particular, in these recent analysis the stroke density to soil has been evaluated referring to 400 circular areas centered at the QuEEN substations' bus-bars monitored and characterized by a $15 \mathrm{~km}$ radius. The sum of $\mathrm{K}$ circular areas centered on $\mathrm{K}$ monitored primary substations is named "Circular Area Monitored"; if K 
corresponds to the all 400 substations $(\mathrm{K}=400)$ this area is named "Total Circular Area Monitored" (TCAM). The voltage dips performance of the network, on the other hand, has been evaluated by means of proper indices which are usually adopted to monitor the network behavior towards voltage dips [4] $\div$ [7].

\section{Correlations between lightning activity and voltage dips indices}

The investigations have first of all regarded the correlations between:

- the weekly stroke density $\mathrm{Ng}$ to the Total Circular Area Monitored;

- the weekly voltage dips indices summarized in Table I normally expressed per measured point

referred to the monitoring period $2009 \div 2011$.

Table I - Voltage dips Indices

\begin{tabular}{|c|l|}
\hline Indices & \multicolumn{1}{|c|}{ Definition } \\
\hline $\mathbf{N}$ & $\begin{array}{l}\text { total number of events occurred in } \\
\text { the monitoring period }\end{array}$ \\
\hline $\begin{array}{c}\text { N2a } \\
\text { (N3b) }\end{array}$ & $\begin{array}{l}\text { total number of events occurred } \\
\text { under class 2 (class 3) immunity } \\
\text { curve }\end{array}$ \\
\hline R-DFI & Regulated Dip Frequency Index [5] \\
\hline DSI_2a & $\begin{array}{l}\text { Discrete Severity Index [6] referred } \\
\text { to class 2 (class 3) immunity curve }\end{array}$ \\
\hline (DSI_3b) & $\begin{array}{l}\text { Missing Voltage Time Area [7] } \\
\text { referred to class 2 (class 3) } \\
\text { immunity curve }\end{array}$ \\
\hline
\end{tabular}

The aim of these preliminary analysis was that of verifying whether the two measurement variables co-vary and quantifying the strength of the relationship between them.

Table II and Figure 1 confirm the existence of a good correlation between the weekly voltage dips indices and the weekly stroke density to soil evaluated referring to the TCAM and limiting the analysis to the spring - summer period. In particular the counting indices $(\mathrm{N}, \mathrm{N} 2 \mathrm{a})$ or the counting by weight index (R-DFI) present a better correlation in comparison with the "energetic" indices (i.e. MVTA2) which show a poor performance. In fact the former indices take into account both all the events and their severity which depends on their position against the immunity curves.

Table II - Correlation Indices*

\begin{tabular}{|l|c|c|c|c|c|c|c|c|}
\hline Monitoring period & $\begin{array}{c}\mathrm{N} \\
\& \mathrm{Ng}\end{array}$ & $\begin{array}{c}\text { N2a } \\
\& \mathrm{Ng}\end{array}$ & $\begin{array}{c}\mathrm{N} 3 \mathrm{~b} \\
\& \mathrm{Ng}\end{array}$ & $\begin{array}{c}\text { MVTA2 } \\
\& \mathrm{Ng}\end{array}$ & $\begin{array}{c}\text { MVTA3 } \\
\& \mathrm{Ng}\end{array}$ & $\begin{array}{c}\text { R-DFI } \\
\& \mathrm{Ng}\end{array}$ & $\begin{array}{c}\text { DSI_2a } \\
\& \mathrm{Ng}\end{array}$ & $\begin{array}{c}\text { DSI_3b } \\
\& \mathrm{Ng}\end{array}$ \\
\hline Apr_Sep_2009-2011 & 0,82 & 0,74 & 0,62 & 0,54 & 0,34 & 0,72 & 0,79 & 0,78 \\
\hline Apr_Sep_2009 & 0,83 & 0,68 & 0,49 & 0,48 & 0,14 & 0,64 & 0,76 & 0,74 \\
\hline Apr_Sep_2010 & 0,87 & 0,83 & 0,72 & 0,69 & 0,61 & 0,81 & 0,85 & 0,84 \\
\hline Apr_Sep_2011 & 0,80 & 0,84 & 0,76 & 0,51 & 0,43 & 0,83 & 0,85 & 0,83 \\
\hline
\end{tabular}

$* \mathrm{Ng}=$ weekly stroke density

The extension of the monitoring period to autumn and winter make the correlation index to drop to 0,51 for the best correlated voltage dip index $(\mathrm{N})$ or to lower values for the others. Figure 2 gives a partial explanation of the drop as it shows that in October - March period it is possible to have a significant monthly value for the number $(\mathrm{N})$ of voltage dips monitored (red curve) and a very low stroke density (blue curve). This fact suggests that in autumn and winter it would be better to consider, as a significant environmental factor on voltage dips occurring in MV lines, the meteorological perturbation as a whole, including lightning, wind, humidity, ice, etc.

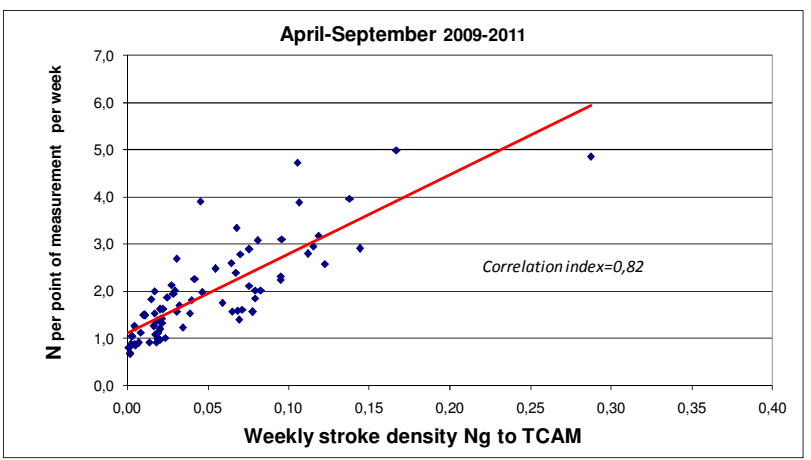

a)

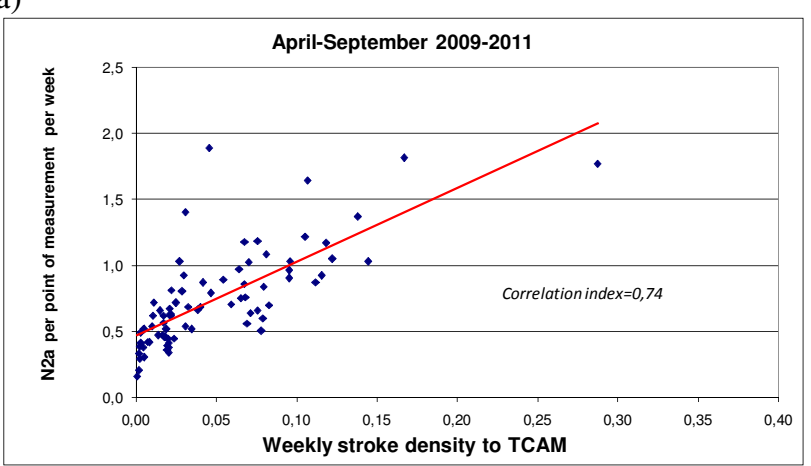

b)

Fig. 1 Correlation between weekly stroke density to Total Circular Area Monitored and respectively a) N b) N2a

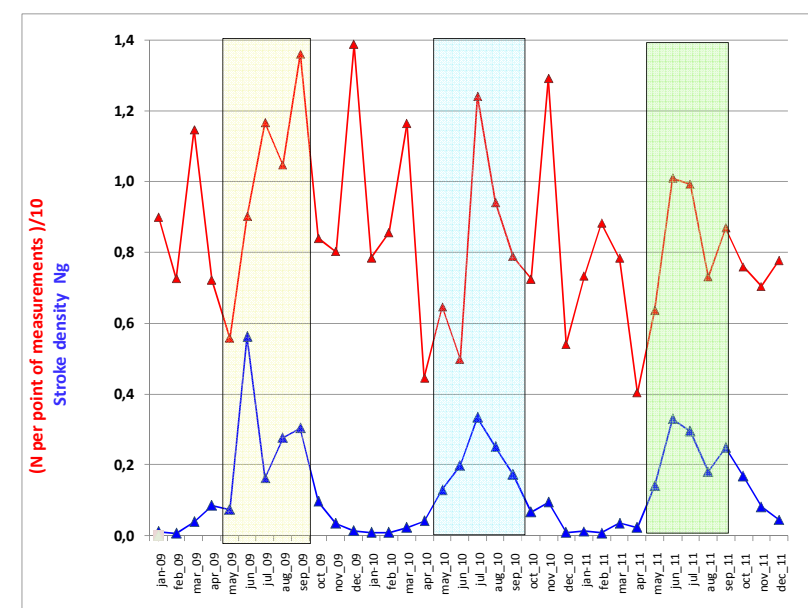

Fig. 2 Monthly trend of $\mathrm{N}$ (red curve) and $\mathrm{Ng}$ (blue curve)

The evaluation of the correlation indices above mentioned at each point of measurement (400 indices) shows an important variation from year to year. The scatter plot in Figure 3 refers, in particular, to the correlation index of $\mathrm{N} 2 \mathrm{a}$ with the stroke density evaluated at each point of measurements respectively in 2009 and 2010. A high correlation in 2009 (Point A: abscissa= 0,98) may correspond to a lower correlation in 2010 (Point B: abscissa $=0,099)$. 


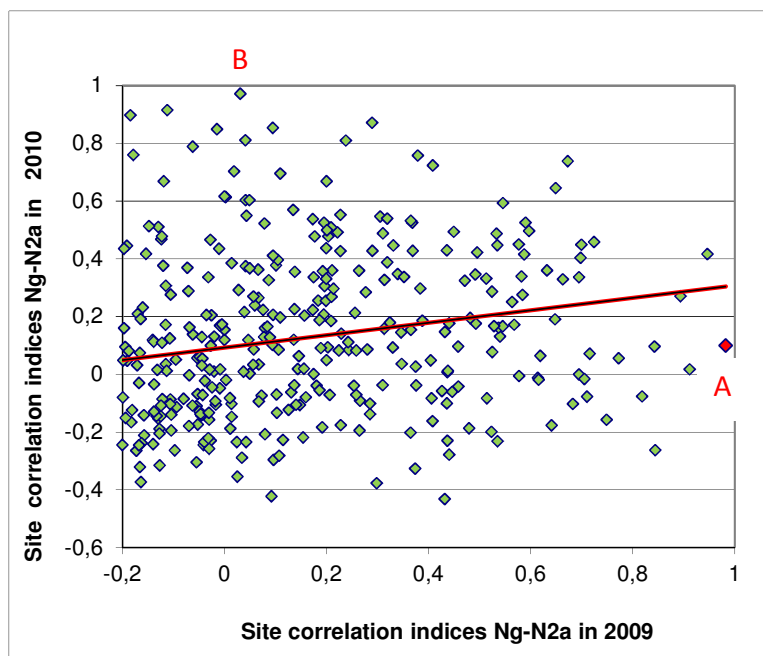

Fig. 3 Site correlation indices Ng - N2a in 2009 vs 2010

\section{Multiple linear regression models}

In order to investigate in more depth the relationship between voltage dips indices (dependent variable or response) and network/environmental characteristics (independent or explanatory variables or predictors) multiple linear regression analysis (MLR) have been applied to $2009 \div 2011$ data. Usually MLR can be used to identify the relationship between a single explanatory variable and the response of the model when all the other explanatory variables in the model are "held fixed", evaluating in this way the following alternatives:

- the influence of each predictor irrespective of the others;

- to estimate the expected response for a given values of the independent variables for forecasting purposes.

In this work MLR has been applied for the first aim, in order to better investigate the influence of each "network characteristics" on voltage dips performance, irrespective of all the other parameters.

A typical MLR model can be expressed as:

$$
I_{i}=\beta_{1} x_{1 i}+\beta_{2} x_{2 i}+\beta_{3} x_{3 i}+\cdots+\beta_{k} x_{k i}+\varepsilon_{i}
$$

where

$\begin{array}{ll}\mathrm{i} & \mathrm{i}^{\text {th }} \text { observation } \\ \mathrm{I}_{\mathrm{i}} & \text { model response } \\ \mathrm{x}_{2 \mathrm{i}} \ldots \mathrm{x}_{\mathrm{ki}} & \text { explicative variables } \\ \beta_{2} \ldots \beta_{\mathrm{k}} & \text { regression coefficients } \\ \varepsilon_{\mathrm{i}} & \text { random error for the } \mathrm{i}^{\text {th }} \text { observation } \\ \beta_{1} & \text { constant which represents the model } \\ & \text { response when the explicative variables } \\ \mathrm{x}_{1 \mathrm{i}} & \text { are null } \\ & \text { unit vector }\end{array}$

As the main object of this work has been that of confirming the validity of the results of previous analogous analysis, having now at disposal a more local measure of stroke density to soil, in comparison with the provincial one used in the past, the MLR models implemented are those that have been resulted as more promising in the past and that are characterized by the explicatory variables listed in Table III. Among the explicative variables the macro - area
[4] and the type of neutral operation are categorical variables as they assume only the values 1 or 0 depending on the belonging or not to a macro area or to the compensated or isolated neutral type of operation of the network. All the other explicative variables are continuous. Two models take into account also the mixed term $\mathrm{L}_{\mathrm{a}} * \mathrm{Ng}$ which is the product of the aerial line length with the stroke density and represents the interaction between the two variables.

Table III. - MLR models

\begin{tabular}{|c|c|c|c|c|}
\hline MLR models & Model 1 & Model 2 & Model 3 & \begin{tabular}{|l|} 
Model 4 \\
\end{tabular} \\
\hline Response & \multirow[t]{2}{*}{$\begin{array}{c}\text { All } \\
\text { indices } \\
\left(^{*}\right)\end{array}$} & \multirow[t]{2}{*}{$\begin{array}{c}\text { All } \\
\text { indices } \\
\left(^{*}\right)\end{array}$} & \multirow[t]{2}{*}{$\begin{array}{c}\text { All } \\
\text { indices } \\
\left({ }^{*}\right)\end{array}$} & \multirow[t]{2}{*}{$\begin{array}{c}\text { All } \\
\text { indices } \\
\left(^{\star}\right)\end{array}$} \\
\hline Explanatory variables & & & & \\
\hline NO (NorthWest) *夫 & $\mathrm{x}$ & $\mathrm{x}$ & $\mathrm{x}$ & $\mathbf{x}$ \\
\hline NE (NorthEast) ** & $\mathbf{x}$ & $\mathbf{x}$ & $\mathbf{x}$ & $\mathbf{x}$ \\
\hline CS (Central part + Sardinia) $)^{\star \star}$ & $\mathbf{x}$ & $\mathbf{x}$ & $\mathbf{x}$ & $x$ \\
\hline Sud (South) ** & $\mathrm{x}$ & $\mathrm{x}$ & $\mathrm{x}$ & $\mathrm{x}$ \\
\hline SN (type of neutral operation) & $\mathrm{x}$ & $\mathrm{x}$ & $\mathbf{x}$ & $\mathbf{x}$ \\
\hline Un (rated voltage) & & & & \\
\hline La (aerial line lenght) & $\mathbf{x}$ & $\mathbf{x}$ & & $\mathbf{x}$ \\
\hline Lc (cable line lenght) & & & & \\
\hline $\mathrm{Ng}$ (stroke density) & $\mathrm{x}$ & & & \\
\hline La*Ng (mixed term) & & & $\mathrm{x}$ & $\mathbf{x}$ \\
\hline
\end{tabular}

The results of the regression models are reported in the Tables IV $\div$ VII. They have been presented for each model in order to point out the percentage contribute of each single explicative variable to the total index under examination evaluated for the monitoring period (three years).

Table IV.- Model 1

\begin{tabular}{|c|c|c|c|c|c|c|}
\hline \multirow[b]{2}{*}{ Explicative variables } & \multicolumn{6}{|c|}{ Model 1} \\
\hline & $\mathbf{N}$ & N2a & N3b & R-DF & DSI_2a & MVTA2 \\
\hline NO (NorthWest) & $4 \%$ & $0 \%$ & $-2 \%$ & $-1 \%$ & $2 \%$ & $-4 \%$ \\
\hline NE (NorthEast) & $1 \%$ & $-2 \%$ & $-5 \%$ & $-3 \%$ & $-1 \%$ & $-9 \%$ \\
\hline CS (Central part + Sardinia) & $4 \%$ & $-2 \%$ & $-5 \%$ & $-3 \%$ & $1 \%$ & $-9 \%$ \\
\hline Sud (South) & $35 \%$ & $39 \%$ & $44 \%$ & $40 \%$ & $37 \%$ & $55 \%$ \\
\hline SN (type of neutral operation) & $12 \%$ & $20 \%$ & $22 \%$ & $21 \%$ & $16 \%$ & $9 \%$ \\
\hline \multicolumn{7}{|l|}{ Un (rated voltage) } \\
\hline La (aerial line lenght) & $26 \%$ & $28 \%$ & $32 \%$ & $29 \%$ & $28 \%$ & $45 \%$ \\
\hline \multicolumn{7}{|l|}{ Lc (cable line lenght) } \\
\hline $\mathrm{Ng}$ (stroke density) & $18 \%$ & $17 \%$ & $15 \%$ & $17 \%$ & $18 \%$ & $14 \%$ \\
\hline $\mathrm{La}^{*} \mathrm{Ng}$ (mixed term) & & & & & & \\
\hline
\end{tabular}

Table V.- Model 2

\begin{tabular}{|c|c|c|c|c|c|c|}
\hline \multirow[b]{2}{*}{ Explicative variables } & \multicolumn{6}{|c|}{ Model 2} \\
\hline & $\mathbf{N}$ & N2a & N3b & R-DFI & DSI_2a & MVTA2 \\
\hline NO (NorthWest) & $9 \%$ & $5 \%$ & $2 \%$ & $4 \%$ & $7 \%$ & $-1 \%$ \\
\hline NE (NorthEast) & $5 \%$ & $1 \%$ & $-2 \%$ & $0 \%$ & $3 \%$ & $-6 \%$ \\
\hline CS (Central part + Sardinia) & $10 \%$ & $4 \%$ & $0 \%$ & $3 \%$ & $7 \%$ & $-4 \%$ \\
\hline Sud (South) & $40 \%$ & $43 \%$ & $47 \%$ & $44 \%$ & $42 \%$ & $58 \%$ \\
\hline SN (type of neutral operation) & $12 \%$ & $20 \%$ & $22 \%$ & $21 \%$ & $15 \%$ & $9 \%$ \\
\hline \multicolumn{7}{|l|}{ Un (rated voltage) } \\
\hline La (aerial line lenght) & $25 \%$ & $27 \%$ & $31 \%$ & $28 \%$ & $26 \%$ & $44 \%$ \\
\hline \multicolumn{7}{|l|}{ Lc (cable line lenght) } \\
\hline \multicolumn{7}{|l|}{$\mathrm{Ng}$ (stroke density) } \\
\hline $\mathrm{La}^{*} \mathrm{Ng}$ (mixed term) & & & & & & \\
\hline
\end{tabular}


Table VI. - Model 3

\begin{tabular}{|l|r|r|r|r|r|r|}
\hline \multirow{2}{*}{ Explicative variables } & \multicolumn{5}{|c|}{ Model 3 } \\
\cline { 2 - 7 } & N & N2a & N3b & R-DFI & DSI_2a & MVT A2 \\
& & & & & & \\
\hline NO (NorthWest) & $10 \%$ & $6 \%$ & $3 \%$ & $5 \%$ & $8 \%$ & $2 \%$ \\
\hline NE (NorthEast) & $7 \%$ & $4 \%$ & $2 \%$ & $4 \%$ & $6 \%$ & $0 \%$ \\
\hline CS (Central part + Sardinia) & $12 \%$ & $7 \%$ & $4 \%$ & $6 \%$ & $10 \%$ & $3 \%$ \\
\hline Sud (South) & $43 \%$ & $47 \%$ & $53 \%$ & $49 \%$ & $46 \%$ & $66 \%$ \\
\hline SN (type of neutral operation) & $16 \%$ & $25 \%$ & $29 \%$ & $26 \%$ & $20 \%$ & $19 \%$ \\
\hline Un (rated voltage) & & & & & & \\
\hline La (aerial line lenght) & & & & & & \\
\hline Lc (cable line lenght) & & & & & & \\
\hline Ng (stroke density) & & & & & & \\
\hline La*Ng (mixed term) & $11 \%$ & $11 \%$ & $9 \%$ & $10 \%$ & $11 \%$ & $10 \%$ \\
\hline
\end{tabular}

\begin{tabular}{|c|c|c|c|c|c|c|}
\hline \multirow[b]{2}{*}{ Explicative variables } & \multicolumn{6}{|c|}{ Model 4} \\
\hline & $\mathbf{N}$ & N2a & N3b & R-DFI & DSI_2a & MVTA2 \\
\hline NO (NorthWest) & $9 \%$ & $5 \%$ & $2 \%$ & $4 \%$ & $7 \%$ & $-1 \%$ \\
\hline NE (NorthEast) & $5 \%$ & $2 \%$ & $-2 \%$ & $1 \%$ & $3 \%$ & $-6 \%$ \\
\hline CS (Central part + Sardinia) & $9 \%$ & $3 \%$ & $-1 \%$ & $2 \%$ & $6 \%$ & $-5 \%$ \\
\hline Sud (South) & $40 \%$ & $43 \%$ & $47 \%$ & $44 \%$ & $42 \%$ & $58 \%$ \\
\hline SN (type of neutral operation) & $12 \%$ & $19 \%$ & $22 \%$ & $20 \%$ & $15 \%$ & $8 \%$ \\
\hline \multicolumn{7}{|l|}{ Un (rated voltage) } \\
\hline La (aerial line lenght) & $16 \%$ & $18 \%$ & $24 \%$ & $20 \%$ & $18 \%$ & $38 \%$ \\
\hline \multicolumn{7}{|l|}{ Lc (cable line lenght) } \\
\hline \multicolumn{7}{|l|}{$\mathrm{Ng}$ (stroke density) } \\
\hline $\mathrm{La}^{*} \mathrm{Ng}$ (mixed term) & $10 \%$ & $10 \%$ & $8 \%$ & $9 \%$ & $10 \%$ & $8 \%$ \\
\hline
\end{tabular}

The presentation method adopted for MLR results allows to overcome the limits presented by the pure knowledge of the coefficients $\beta_{2} \ldots \beta_{\mathrm{k}}$ directly supplied by the models. These last ones cannot in fact provide an overall view of the contribute of each single explicative variable as they are dimensional coefficients, characterized by different measure units, different from that ones of the model response. The procedure applied, widely explained in [2], starts from these coefficients directly supplied by the MLR models and associated to a week period, to point out how each explicative variable could contribute to the total phenomena observed during the whole monitoring period. Table VIII summarizes, for the different responses of the models $(\mathrm{N}, \mathrm{N} 2 \mathrm{a}, \ldots)$ and for the different models, the determination coefficients $\mathrm{R}^{2}$ evaluated in the period 2009 $\div 2011$. It is common knowledge that $\mathrm{R}^{2}$ is a measure of the overall quality of the regression as it represents the percentage of the total variation in the model response that is accounted for by the regression model.

Table VIII. - Determination coefficients

\begin{tabular}{|c|c|c|c|c|c|c|}
\hline \multicolumn{7}{|c|}{$R^{2}$ evaluation } \\
\hline $\mathrm{R}^{2}$ & $\mathbf{N}$ & N2a & N3b & R-DFI & DSI_2a & MVTA2 \\
\hline model 1 & 0.51 & 0.43 & 0.36 & 0.42 & 0.47 & 0.36 \\
\hline model 2 & 0.49 & 0.42 & 0.36 & 0.41 & 0.46 & 0.36 \\
\hline model 3 & 0.45 & 0.39 & 0.33 & 0.38 & 0.42 & 0.31 \\
\hline model 4 & 0.49 & 0.42 & 0.36 & 0.41 & 0.46 & 0.36 \\
\hline
\end{tabular}

Model 1, which takes into account $\mathrm{L}_{\mathrm{a}}$ and $\mathrm{Ng}$ separately, confirms itself as the best significant model being characterized by the highest value of $\mathrm{R}^{2}$, whatever is the voltage dip indices or response involved in the regression. Model 3 can be considered an alternative to Model 1, being characterized by the presence of the mixed term $\mathrm{L}_{\mathrm{a}}{ }^{*} \mathrm{Ng}$. In particular this model is characterized by an increase of the coefficients associated to the belonging to a macro area
(Table IV and Table VI). As to Model 2 it can be considered a reference model in which no environmental factor has been taken into account. Nevertheless the lack of stroke density in this model does not change the contribution of the explicative variable $\mathrm{L}_{\mathrm{a}}$ to the total estimation. Model 4 does not provide any improvement in $\mathrm{R}^{2}$ evaluation with respect to Model 2 even if considers both $\mathrm{L}_{\mathrm{a}}$ and the mixed term $\mathrm{L}_{\mathrm{a}}{ }^{*} \mathrm{Ng}$ as explicative variables.

\section{Results}

The analysis of the tables presented in the previous paragraph lead to the following results:

- aerial lines length has always a meaningful effect on voltage dips indices (percentage contribution within the $25 \%-30 \%$ range). Slightly lower values can be obtained only for Model 4 which considers at once both the $\mathrm{L}_{\mathrm{a}}$ and the mixed term $\mathrm{L}_{\mathrm{a}}$ *Ng contributions;

- cable lines length seems, as expected, to have a negligible effect if compared to the influence of other parameters;

- the neutral type of compensation has somehow a positive effect on voltage-dips performance even if its contribution do not appear as significant as the aerial line length one (the contribution is within the range $12 \%$ and $19 \%$ );

- the lightning activity on voltage dips performances in MV networks does not seem to show the expected effects. It plays a significant role (percentage contribution within the $15 \% \div 18 \%$ range) but not as much as the line length does, even if more localized stroke density data were at disposal;

- it is possible to confirm the strong dependence of the different voltage dips indices on the belonging to a particular geographical area. This dependence can be evaluated from the percentage contributions offered by the four macro area constants (contribution which reveals particularly important for the macro area South).

\section{Conclusion}

The influence that some network and environmental parameters may have on the number of voltage dips monitored in MV networks has been investigated by both correlation and multiple regression analysis techniques, applied to PQ and lightning data acquired along the treeyears period $2009 \div 2011$. The performed correlations between the weekly voltage dip indices of the whole monitored network and the weekly lightning density to soil referred to the TCAM have shown:

- a good correlation in the spring-summer period (correlation index $=0,7 \div 0,8$ );

- a drop to 0,51 extending the monitoring period to autumn and winter;

- $\quad$ significant variations from year to year at each point of measurements. 
Multiple linear regression analysis has confirmed that:

- aerial lines length has always a meaningful effect on voltage dips indices;

- cable lines length seems, as expected, to have a negligible effect if compared to the influence of other parameters;

- the neutral compensation has somehow a positive effect on voltage dips performance but its contribution do not appear as significant as the aerial line length one;

- the lightning activity influence on voltage dips performances does not seem to show the expected results;

- $\quad$ voltage dips statistic depends in a not negligible way on the geographical area where the monitoring unit has been installed.

Future activity will be focused on the correlation of the voltage dips performance with the meteorological perturbation as a whole, including f.i. lightning, wind, humidity and ice to take into account other environmental factors more relevant to winter months.

\section{Acknowledgement}

This work has been financed by the Research Fund for the Italian Electrical System under the Contract Agreement between RSE S.p.A. and the Ministry of Economic Development - General Directorate for Nuclear Energy, Renewable Energy and Energy Efficiency in compliance with the Decree of March 8, 2006.

\section{References}

[1] F. Villa, A. Porrino, R. Chiumeo, S. Malgarotti, "The power quality monitoring of the MV network promoted by the Italian regulator", 19th International Conference on Electricity Distribution, CIRED 2007, Vienna, paper 0042.

[2] Rapporto CESI RICERCA 08005783 "Sistema di monitoraggio della qualità della tensione: evoluzione del sistema a supporto dell'attività regolatoria e delle proposte di revisione della normativa tecnica europea ", Febbraio 2009, www.rse-web.it, (in Italian).

[3] R. Chiumeo and L. Tenti, "The results of MV networks monitoring in Italy", presentation at the "Regulation of voltage quality for the Italian network" Workshop organized by the Italian Regulatory Authority for Electricity and Gas (AEEG) and by the Politecnico di Milano, Bergamo, Italy 29th September 2010.

[4] R. Chiumeo, L. Garbero, L. Tenti, C. Gandolfi, M. de Nigris "The voltage dip performance assessment of the Italian MV network through global indices", $21^{\text {st }}$ International Conference on Electricity Distribution, CIRED 2011, Frankfurt, paper 0886.

[5] R. Chiumeo, L. Garbero, L. Tenti, "Rapporto sintetico sulle prestazioni della rete di distribuzione italiana in media tensione con riferimento ai buchi di tensione", Appendice D al documento di consultazione dell'Autorità per l'energia elettrica ed il Gas DCO 42/10, Novembre 2010 (in Italian).

[6] G. Carpinelli, P. Caramia, P. Verde, P. Varilone, R. Chiumeo, I. Mastandrea, F. Tarsia, "A Global Index for Discrete Voltage Disturbances", 9th International Conference Electrical Power Quality and Utilization, EPQU 2007, Barcelona.

[7] A. M. Dan, "Introducing a voltage dip severity index: a proposal", 14th International Conference on Harmonics and Quality of Power, ICHQP 2010, Bergamo, paper 201. 